\title{
Applying Conflict Management Styles to Resolve Task Conflict and Enhance Team Innovation
}

\author{
Anh Tho To ${ }^{1 *}$, Thi Siem Tran ${ }^{1}$, Kieu Oanh Nguyen ${ }^{1}$, Van Trung Hoang ${ }^{1}$, \\ Kim Phong Thai ${ }^{1}$ \\ ${ }^{1}$ University of Finance - Marketing, Ho Chi Minh City, Vietnam
}

\begin{abstract}
Task conflicts among group members have a significant impact on team creativity, so it is critical to identify which conflict resolution styles should be used. This paper aims to examine how various conflict management styles influence team creativity via task conflict. The empirical research was conducted using the Structural Equation Model (SEM) for a sample of 257 employees working for Vietnamese organizations. The results show that dominating style increases task conflict while combining and obliging styles reduce it. To take advantage of the creativity-related benefits associated with task conflict, team leaders should develop an open atmosphere that encourages participants' integrating styles, rather than dominating styles. The negative influence of obliging style reflects Vietnamese culture's high collectivism. The study provides various approaches for task conflict management and also highlights the role of controlling task conflicts in enhancing team innovation. It implies that employees will be able to work better as a team in practice if conflict management strategies are used in a flexible manner. It helps them to build a good connection and successfully implement new ideas. Further research should extend the conclusion of this analysis in various contexts to generalize the findings.
\end{abstract}

\section{Keywords:}

Conflict;

Team Innovation;

Conflict Management;

Vietnam.

\section{Article History:}

$\begin{array}{llll}\text { Received: } & 22 & \text { May } & 2021 \\ \text { Revised: } & 27 & \text { August } & 2021 \\ \text { Accepted: } & 07 & \text { September } & 2021 \\ \text { Published: } & 01 & \text { October } & 2021\end{array}$

\section{1- Introduction}

Conflict is an unavoidable and normal event in any organization. Organizations have been faced with structural, personnel, and resource distribution issues as a result of industrialization and globalization, resulting in different forms of conflict [1]. Employees participate in different types of confrontation, which wastes organizational capital. The degree to which conflict has a positive or negative effect on an organization is determined by the types of conflict and how it is treated. Human resource managers have applied a variety of styles (dominating, obliging, and integrating) for resolving conflicts and working cooperatively so far.

In addition, task conflict and relationship conflict are two forms of conflict. Task conflict, which is characterized by task inconsistency, results in the team's failure to achieve the target. Relationship conflict involves relational or personal problems that can endanger the relationship between the two parties. While some studies have listed both task and relationship conflict, this study focuses exclusively on task conflict because relationship conflict undermines organizational performance and stakeholder satisfaction, thus it should be avoided [2].

Moreover, the impact of task conflict on team creativity has been inconsistent or unclear. It may gives rise to debate between different viewpoints, thereby leading to increased team creativity [3]. The debates are likely to foster

*CONTACT: totho@ufm.edu.vn

DOI: http://dx.doi.org/10.28991/esj-2021-01303

(C) 2021 by the authors. Licensee ESJ, Italy. This is an open access article under the terms and conditions of the Creative Commons Attribution (CC-BY) license (https://creativecommons.org/licenses/by/4.0/). 
organizational communication and exchange of work-related opinions, thoughts. Nonetheless, a high level of task conflict might be detrimental to team effectiveness [4]. Meanwhile, other researchers have used a contingency method to determine if task conflict improves or degrades a range of team outcomes, including creativity [5].

More notably, Vietnamese culture is characterized by strong collectivism, power distance, conservatism, and paternalism [6]. It is contrast to individualistic cultures like the United States and Western Europe. Therefore, examining the impact of task conflict on team creativity in Vietnam, where opposing viewpoints are not often welcomed and a united collective voice and harmony are usually viewed as desired [7], is a conservative test. It motivates us to investigate the influence of conflict management styles on team creativity through task conflict in Vietnam - an emerging market.

This article is structured as follows: The second section includes a literature review and the development of hypotheses. The research process and research model are discussed in the following section. The results of the study are summarized in Section 4. Conclusions and implications for clinicians and scholars are discussed in Section 5.

\section{2- Literature Review and Hypothesis Development}

\section{2-1-Task Conflict}

Workplace conflict has been proven to be inevitable in various studies. The difference in opinion, beliefs, views among employees leads to task conflict or relationship conflict [8]. Relationship conflicts are based on relationship problems that result from individual differences as well as differences in opinion and interests on non-task issues like religion, politics, and fashion, while task conflicts involve differences of viewpoints, ideas, and opinions in the group about the goals or content of the task being performed [9]. Employees usually consider the conflicts as "work disagreements", "work conflict", and "task problems". Rahim (2001) [10] defined task conflict as "conflict occurring when two or more organizational members disagree on their task or content issues". However, it has been proven in various studies that its mere presence is not the issue, but how it is managed determines whether conflict leads to a constructive or destructive outcome.

\section{2-2-Conflict Management Styles}

The way how a group member deals with the conflict is explained through various conflict management styles. A five-style or three-style model can be used to present the fundamental approaches [11]. Thomas (2008) [12] suggested five conflict resolution types: competing, collaborating, compromising, avoiding, and accommodating. Rahim (1983) [13] also introduces a five-style model focused on two aspects of "concern for self or others": dominating, integrating, obliging, avoiding, compromising. However, the components of a five-style model can be reduced and integrated into three specific conflict styles: (a) forcing or dominating, (b) solution-oriented or integrating, and (c) smoothing or obliging [14]. Our research follows a three-style approach.

\section{Dominating style (Win-Lose strategy)}

This style is characterized by a high degree of concern for oneself and a low level of concern for others, suggesting a win-lose strategy or pushing actions to achieve one's own position or goal without regard for others. This style displays a violent, inflexible approach and shows competing attitudes linked with aggression [15]. Using a dominating style could lead to higher levels of conflict, so it is appropriate in urgent situations or for an unimportant problem [16].

\section{H1: Dominating style has a positive impact on task conflict.}

\section{Obliging style (Lose-Win Strategy)}

This style is also known as accommodating which emerges from a lack of concern for oneself and a strong concern for others. Individuals with an obliging style tend to place others' interests ahead of their own, downplaying discrepancies and emphasizing commonalities to persuade others' concerns [17]. This obligating style is applied while individuals display self-dedicated behavior by ignoring their needs for the other group, habitually resulting in a losewin outcome. This style can also be used to preserve a relationship especially when the relationship is more important than the issue. It may be appropriate for Asian working environments because Asian countries' character is mostly collectivism [18].

\section{H2: Obliging style has a negative impact on task conflict.}

\section{Integrating style (Win-Win Strategy)}

This approach focuses on working together to find a solution, indicating a strong concern for oneself and others. It reflects openness, information sharing, and a thorough analysis of disparities to get an efficient solution that is agreeable to all parties. In other words, Individuals who are involved in conflicts try to come up with creative and imaginative approaches that not only satisfy their own needs but also meet those of others [19]. When the problems are complicated, this style works well in integrating the expertise and knowledge of multiple parties to formulate and execute ideas 
effectively. This style is often linked to less task conflict [20]. As a result, the integrating style is seen as efficient and sufficient in settling conflicts. Integrating and accommodating styles assist workgroup participants in getting to know one another better and feeling prepared to complete tasks.

\section{H3: Integrating style has a negative impact on task conflict.}

\section{2-3- Team Innovation}

Team creativity is described as the product of efforts to develop and incorporate new and improved ways of doing things [21]. It is the creation and development of new concepts, practices, or processes that are helpful to the team [22]. Researchers have used a contingency approach to find out whether task conflict improves or damages team outcomes (including innovation) when considering the relationship between task conflict and creativity [23].

First, some previous studies have found that task conflict has a positive effect on team creativity [24]. Task conflict is likely to encourage various thoughts and the exchanging of a wider variety of ideas on related issues at the workplace [25]. When a workgroup is faced with task disputes, they are more innovative in their thinking [26]. Minor conflicts can inspire group members to seek better options or solutions [27]. Since diverse views and experiences are exchanged, constructive dialogue and conversation are likely to boost a team's innovation. Conflict is likely to encourage learning and the generation of fresh, potentially innovative ideas, resulting in a more competitive and inventive team [28].

On the contrary, many researchers have noted the negative impact of task conflict on team effectiveness. Job disagreement hinders one's ability to interpret, absorb, and analyze knowledge [29], which can have a negative effect on creativity. Where there is a lot of task tension, the role of the team members executing the task becomes more ambiguous, and success declines as a result. When task-related disagreement grows, teams are less able to form and sustain cohesive teams [30]. As a result, team members are less able to work well or produce new strategies or solutions. As a result, we believe task conflict has a negative impact on team performance.

H4: Task conflict is negatively related to team innovation.

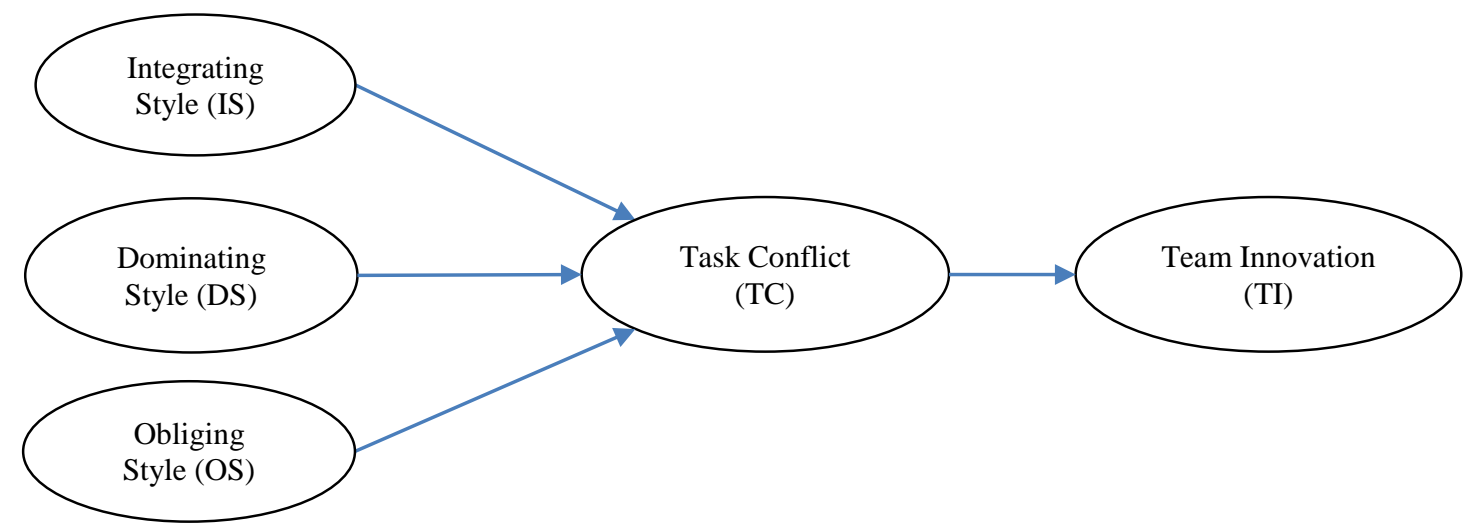

Figure 1. The proposed research model.

\section{3- Research Methodology}

\section{3-1-Data}

Primary data for hypotheses testing was collected from full-time employees working for companies or organizations in Ho Chi Minh City, Vietnam, using an online survey questionnaire. There are seven items for integrating style, five for obliging style, three for dominating style, three for task conflict, and six for team innovation in the questionnaire. Items used in this study were all originally written in English, but participants are Vietnamese. The survey items were first translated into Vietnamese, then back-translated into English by bilingual experts and researchers to reconcile all differences and refine the wording. Five research associates with expertise in human resource administration pre-tested and then updated a draft of the questionnaire in Vietnam. The survey was reviewed by 30 staff from various organizations to identify problems with terminology, content, and question ambiguity. Some minor changes were made in response to their feedback. After we conducted an official survey, out of 320 responses, 257 were appropriate.

As shown in Table 1, the demographic profile of the respondents indicates that the sample consisted of more females $(56.4 \%)$ than males $(43.6 \%)$ but this difference only accounts for less than $15 \%$. With regards to age, the majority of employees (26.8\%) belong to the age group of 25 to less than 30 years old and the results also showed that there is a fair mix of age groups. 65 percent of the participants in the study have a bachelor's degree, while $18.7 \%$ have a master's degree. In terms of experience, the majority of respondents $(51.8 \%)$ have fewer than three years of experience. 
Table 1. Respondents' profile.

\begin{tabular}{|c|c|c|c|}
\hline Measure & Value & Frequency & Percent \\
\hline \multirow{2}{*}{ Gender } & Female & 145 & $56.4 \%$ \\
\hline & Male & 112 & $43.6 \%$ \\
\hline \multirow{6}{*}{ Age } & Below 25 years & 61 & $23.7 \%$ \\
\hline & 25 to below 30 years & 69 & $26.8 \%$ \\
\hline & 30 to below 35 years & 46 & $17.9 \%$ \\
\hline & 35 to below 40 years & 36 & $14.0 \%$ \\
\hline & 40 to below 45 years & 35 & $13.6 \%$ \\
\hline & 45 years and above & 10 & $3.9 \%$ \\
\hline \multirow{4}{*}{ Education } & High school & 38 & $14.8 \%$ \\
\hline & Bachelor & 167 & $65.0 \%$ \\
\hline & Master & 48 & $18.7 \%$ \\
\hline & Doctor & 4 & $1.6 \%$ \\
\hline \multirow{2}{*}{ Occupation } & Government & 80 & $31.1 \%$ \\
\hline & Non-government & 177 & $68.9 \%$ \\
\hline \multirow{4}{*}{ Income } & Less than 10 million VND & 101 & $39.3 \%$ \\
\hline & 10 to below 20 million VND & 101 & $39.3 \%$ \\
\hline & 20 to below 30 million VND & 21 & $8.2 \%$ \\
\hline & 30 million VND and above & 34 & $13.2 \%$ \\
\hline \multirow{5}{*}{ Experience } & Below 3 years & 133 & $51.8 \%$ \\
\hline & 3 to below 5 years & 34 & $13.2 \%$ \\
\hline & 5 to below 7 years & 19 & $7.4 \%$ \\
\hline & 7 to below 10 years & 19 & $7.4 \%$ \\
\hline & 10 years and above & 52 & $20.2 \%$ \\
\hline
\end{tabular}

\section{3-2-Measures}

The items used for each model in this analysis were adapted from previous studies (as shown in Appendix I). First, conflict management styles were created using the Rahim (1983)'s Organizational Conflict Inventory-II as cited earlier. The scale's validity is demonstrated by its ability to differ conflict management styles. As mentioned above, the components of a five-style model can be reduced and integrated into a three-style model: (a) forcing or dominating, (b) solution-oriented or integrating, and (c) smoothing or obliging. Although Rahim's original scale were elicited for all five conflict-management styles, this study only focused on the three conflict-management strategies (dominating, integrating, and obliging). The Likert scale responses ranged from strongly disagreement (1) to strongly agreement (7).

Next, we evaluated team creativity using Anderson and West (1998)'s scale [31], which refers to employees' perceptions of the team's ability to generate and share new ideas. The following are two sample items for innovation: "My team is always moving toward the development of new answers" and "People in the team co-operate to help develop and apply new ideas". A seven-point Likert scale ( $1=$ total disagreement, $7=$ total agreement $)$ was used to collect data on team innovation.

Finally, we used three items developed by Jehn and Mannix (2001) [32] to measure task conflict, with the scale describing overall workplace task conflict. This scale is also used by Yu and Mary (2018) [33] and Tafvelin (2020) [34]. The participants, for example, were asked to respond to the item: "How frequently do you have disagreements within your team about the task of the project you are working on". Participants indicated how much they related to the content of each item, using a Likert-style scale ranging from $1=$ none to $7=$ a great deal. We applied the Brislin's method [35] to translate all survey instruments from English to Vietnamese: (1) A native Vietnamese speaker who was fluent at English translated the original scales into Vietnamese; (2) A bilingual professional translator who was blinded to backtranslate the original version into English; (3) the authors compared and found no discrepancies between the two versions.

\section{3-3-Data Analysis}

Partial least squares structural equation modeling (PLS-SEM) was used to evaluate our theoretical model. This method is commonly used in business and management research [14]. PLS-SEM solves several problems of covariancebased structural equation modeling (CB-SEM). First, PLS-SEM provides accurate model estimations for small sample sizes [36]. The minimum recommended sample size for PLS-SEM, according to Chin \& Newsted (1999) [37], is 30 to 
100. Second, unlike CB-SEM based on maximum probability, PLS-SEM is a nonparametric method that does not assume data is normally distributed.

To test the proposed models, we used SmartPLS version 3.0 and the two-step analysis technique. First, we checked the validity and reliability of the measures. Second, we use a bootstrapping approach (1000 resamples) to determine the significance levels for path coefficients.



Figure 2. Flowchart of the study.

\section{4- Results}

\section{4-1-Measurement Model Assessment}

The reliability and validity of the construct measures are used to evaluate the measurement model. The criteria such as internal consistency reliability, convergent validity, and discriminant validity were proposed by Hair et al. (2017) [38]. The internal consistency reliability of constructs was first tested using composite reliability (CR) and Cronbach's alpha. The CR and Cronbach alpha scores in the study were also higher than the cut-off value of 0.7 , as seen in Table 4 . Second, the outer loadings of the indicators and the average variance extracted were used to determine convergent validity (AVE). Items with outer loadings greater than 0.40 should be kept for analysis. In this analysis, all outer loadings were greater than 0.7. Another standard criterion for determining convergent validity at the construct level is AVE. AVE was greater than 0.5 , suggesting that the construct explained more than half of the variance of its indicators [39]. Third, in terms of discriminant validity, we made sure that each construct's square root of AVE was greater than its association with other constructs. The Heterotrait-Monotrait (HTMT) values were also smaller than the 0.85 thresholds [40]. As shown in Tables 2 and 3, our analysis has discriminant validity.

Table 2. Fornell-Larcker criterion.

\begin{tabular}{|c|c|c|c|c|c|}
\hline & Dominating style & Integrating style & Obliging style & Task conflict & Team innovation \\
\hline Dominating style & 0.888 & & & & \\
\hline Integrating style & 0.036 & 0.843 & & & \\
\hline Obliging style & -0.145 & -0.096 & 0.793 & & \\
\hline Task conflict & 0.395 & -0.157 & -0.225 & 0.892 & \\
\hline Team innovation & 0.076 & 0.591 & -0.167 & -0.191 & 0.861 \\
\hline
\end{tabular}

Table 3. HTMT ratio analysis.

\begin{tabular}{|c|c|c|c|c|c|}
\hline & Dominating style & Integrating style & Obliging style & Task conflict & Team innovation \\
\hline Dominating style & & & & & \\
\hline Integrating style & 0.065 & & & & \\
\hline Obliging style & 0.149 & 0.161 & & & \\
\hline Task conflict & 0.414 & 0.136 & 0.206 & & \\
\hline Team innovation & 0.108 & 0.650 & 0.223 & 0.197 & \\
\hline
\end{tabular}


Table 4. Outer loadings, AVE, CR, and Cronbach's Alpha.

\begin{tabular}{|c|c|c|c|c|c|}
\hline Constructs & Measurement & Outer loadings & Cronbach's Alpha & $\mathbf{C R}$ & AVE \\
\hline \multirow{3}{*}{ Dominating style (DS) } & DS 1 & 0.828 & \multirow{3}{*}{0.869} & \multirow{3}{*}{0.918} & \multirow{3}{*}{0.789} \\
\hline & DS 2 & 0.918 & & & \\
\hline & DS 3 & 0.916 & & & \\
\hline \multirow{5}{*}{ Obliging style (OS) } & OS 1 & 0.731 & \multirow{5}{*}{0.864} & \multirow{5}{*}{0.894} & \multirow{5}{*}{0.629} \\
\hline & OS 2 & 0.799 & & & \\
\hline & OS 3 & 0.725 & & & \\
\hline & OS 4 & 0.863 & & & \\
\hline & OS 5 & 0.836 & & & \\
\hline \multirow{7}{*}{ Integrating style (IS) } & IS 1 & 0.737 & \multirow{7}{*}{0.940} & \multirow{7}{*}{0.945} & \multirow{7}{*}{0.711} \\
\hline & IS 2 & 0.733 & & & \\
\hline & IS 3 & 0.832 & & & \\
\hline & IS 4 & 0.866 & & & \\
\hline & IS 5 & 0.910 & & & \\
\hline & IS 6 & 0.898 & & & \\
\hline & IS 7 & 0.907 & & & \\
\hline \multirow{3}{*}{ Task conflict (TC) } & TC 1 & 0.830 & \multirow{3}{*}{0.875} & \multirow{3}{*}{0.921} & \multirow{3}{*}{0.795} \\
\hline & TC 2 & 0.926 & & & \\
\hline & TC 3 & 0.915 & & & \\
\hline \multirow{6}{*}{ Team innovation (TI) } & TI 1 & 0.843 & \multirow{6}{*}{0.931} & \multirow{6}{*}{0.945} & \multirow{6}{*}{0.742} \\
\hline & TI 2 & 0.839 & & & \\
\hline & TI 3 & 0.881 & & & \\
\hline & TI 4 & 0.864 & & & \\
\hline & TI 5 & 0.875 & & & \\
\hline & TI 6 & 0.865 & & & \\
\hline
\end{tabular}

\section{4-2-Structural Model Assessment}

Before testing hypotheses, we checked for collinearity between constructs. Collinearity was investigated using the variance inflation factor (VIF) value. Since all VIF values were below the threshold of 5, collinearity among the constructs was not a significant issue in this analysis.

Table 5. Results of a structural equation modelling.

\begin{tabular}{|c|c|c|c|c|c|}
\hline Hypotheses & Coefficients & T Statistics & P Values & f square & Support \\
\hline H1: Dominating style $\rightarrow$ Task conflict & 0.375 & 7.435 & 0.000 & 0.176 & Accepted \\
\hline H2: Integrating style $\rightarrow$ Task conflict & -0.189 & 2.543 & 0.011 & 0.045 & Accepted \\
\hline H4: Task conflict $\rightarrow$ Team innovation & -0.191 & 3.432 & 0.001 & 0.038 & Accepted \\
\hline
\end{tabular}

By bootstrapping 1,000 samples, the P-values were used to determine the statistical significance of our hypotheses. The key parameters obtained for the model in the structural evaluation are depicted in Figure 3. First, we tested the relationship between conflict management styles and task conflict. Table 5 reveals that dominating style has a significant positive impact on task conflict $(\beta=0.375, \mathrm{p}=0.000)$, while integrating and obliging styles have significant negative effects $(\beta=-0.189, \mathrm{p}=0.011$; and $=-0.188, \mathrm{p}=0.000$, respectively). The findings are consistent with the findings of Darawong (2017), who studies the direct effect of conflict management styles on task conflict and relationship conflict between marketing and R\&D staff in Thai manufacturing companies throughout the new product development process [41]. Individuals who use a dominating style tend to actively use their intelligence, experience, and power to defeat the ideas of others, regardless of the other party. When members of a group use an integrating style, on the other hand, they are more likely to share thoughts and listen openly to others in order to find the best solution. Task-related information is incorporated into the communication and decision-making process, resulting in a low probability of task conflict. An integrating style encourages positive project improvements, while a dominant style leads to violent conflict. Regarding obliging style, it can improve cohesion and social desirability, reducing task conflict. Vietnamese people, like Thais, showed a preference for obliging style [42] because Asians frequently want to maintain a good connection with another party, and they will typically try to make compromises to suit the other party's requirements, establish harmony, and also show the high degree of collaboration [43]. 


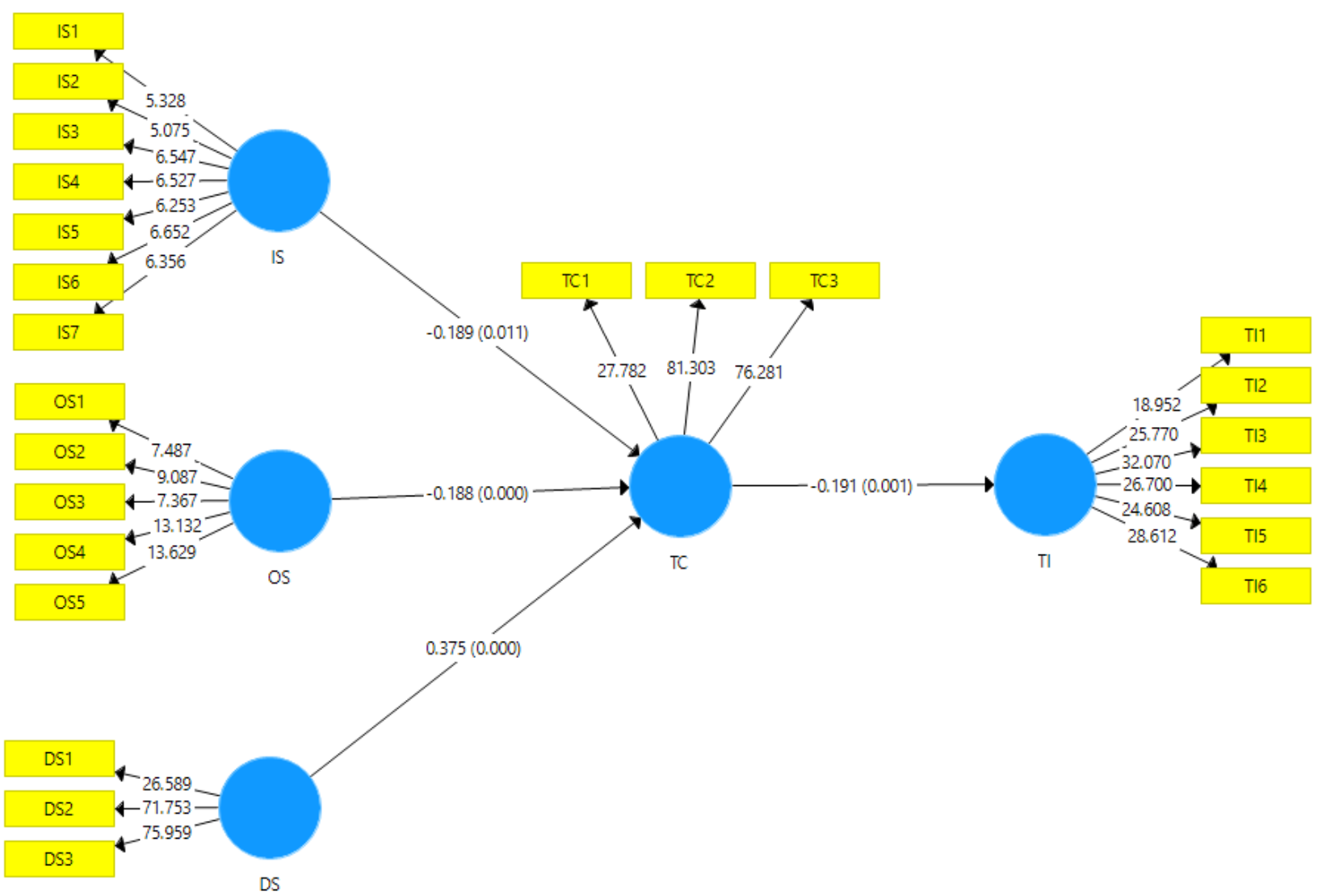

Figure 3. Results of the structural model.

Which conflict styles are chosen depends much on the situation. Employees' conflict solving strategies are influenced by culture [44]; for example, it can be expected that collectivism is favorably correlated with integrating and obliging styles. For example, Indonesians, who are collectivists, favor incorporating and obliging models, while Americans, who are individualistic, prefer integrating and dominating styles [45]. Hence, our findings may be appropriate for Asian working environments because Asian countries' character is mostly collectivism.

Second, we discovered evidence for $\mathrm{H} 4$, which predicted a negative association between task conflict and team innovation $(\beta=-0.191, p=0.001)$. High levels of task conflict can cause cognitive overload or negative emotion, both of which are detrimental to team creativity. In other words, conflicts and frustrations stifle team cooperation, which is essential for creating, assessing, and choosing the most innovative and creative ideas. Individuals' ability to interact, cooperate, and organize efficiently is impaired by task conflict [46]. As De Dreu (2006), as cited earlier, also stated: "Increasingly high compared to moderate levels of task conflict, however, produce the stress, interpersonal tension, and distrust that prohibit people from focusing on the problem and from open-mindedly generating ideas. It also reduces team members' motivation to work together in selecting and implementing adequate problem solutions".

The effect size $\mathrm{f}^{2}$ determines whether an exogenous construct has a significant influence on an endogenous construct. $0.02,0.15$, and 0.35 were used to describe small, medium, and large effects, respectively [47]. The $\mathrm{f}^{2}$ values for all combinations of endogenous and exogenous constructs are also reported in Table 5. The effect sizes for all exogenous latent variables were greater than 0.02 , meaning that they had small to medium effects.

\section{5- Conclusion}

This study contributed to the philosophy of conflict management by examining how different types of conflict management influence task conflict. The results show that dominating style increases task conflict while combining and obliging styles reduce it. This study also presents that task conflict has a negative effect on team creativity. High levels of task tension can lead to negative emotional feelings and, as a result, a reduction in team creativity. Our results imply that team leaders who want to boost innovation should keep task conflict in control. They can create contact networks from which members can communicate and collect feedback, for example, to hold task conflict to a minimum. However, all of the responses were limited to the Vietnam context, which may reduce the generalizability of our results. Vietnam's cultural, economic, and institutional mechanisms have been reported to be different from developed countries. Therefore, researchers should be cautious when extending the conclusion of this analysis in other contexts. 


\section{6- Declarations}

\section{6-1-Author Contributions}

Conceptualization, A.T.T., T.S.T.; writing - original draft preparation, A.T.T, K.O.N., H.V.T.; writing-review and editing, A.T.T., T.S.T., K.P.T. All authors have read and agreed to the published version of the manuscript.

\section{6-2-Data Availability Statement}

The data presented in this study are available in article.

\section{6-3- Funding}

The authors received the financial support from the University of Finance - Marketing for the research.

\section{6-4- Conflicts of Interest}

The authors declare that there is no conflict of interests regarding the publication of this manuscript. In addition, the ethical issues, including plagiarism, informed consent, misconduct, data fabrication and/or falsification, double publication and/or submission, and redundancies have been completely observed by the authors.

\section{7- References}

[1] Caputo, Andrea, Oluremi B. Ayoko, and Nii Amoo. "The Moderating Role of Cultural Intelligence in the Relationship between Cultural Orientations and Conflict Management Styles.” Journal of Business Research 89 (August 2018): 10-20. doi:10.1016/j.jbusres.2018.03.042.

[2] Jung, Eun Jin, and Sujin Lee. "The Combined Effects of Relationship Conflict and the Relational Self on Creativity." Organizational Behavior and Human Decision Processes 130 (September 2015): 44-57. doi:10.1016/j.obhdp.2015.06.006.

[3] Farh, Jiing-Lih, Cynthia Lee, and Crystal I. C. Farh. "Task Conflict and Team Creativity: A Question of How Much and When." Journal of Applied Psychology 95, no. 6 (November 2010): 1173-1180. doi:10.1037/a0020015.

[4] De Dreu, Carsten K. W., and Laurie R. Weingart. “Task versus Relationship Conflict, Team Performance, and Team Member Satisfaction: A Meta-Analysis.” Journal of Applied Psychology 88, no. 4 (2003): 741-749. doi:10.1037/0021-9010.88.4.741.

[5] O'Neill, Thomas A., Natalie J. Allen, and Stephanie E. Hastings. "Examining the 'Pros' and 'Cons' of TeamConflict: A TeamLevel Meta-Analysis of Task, Relationship, and Process Conflict.” Human Performance 26, no. 3 (July 2013): 236-260. doi:10.1080/08959285.2013.795573.

[6] Putra, Andi Manggala, Gagaring Pagalung, and Abdul Hamid Habbe. "Level of Agency Cost Driven by Cultural and Corruption and Earnings Management: Evidence of South East Asia Countries.” Intangible Capital 14, no. 4 (September 28, 2018): $499-517$. doi:10.3926/ic.1289.

[7] Lee, Eun Kyung, Ariel C. Avgar, Won-Woo Park, and Daejeong Choi. “The Dual Effects of Task Conflict on Team Creativity." International Journal of Conflict Management 30, no. 1 (February 11, 2019): 132-154. doi:10.1108/ijcma-02-2018-0025.

[8] Jehn, Karen A, and Corinne Bendersky. "Intragroup Conflict in Organizations: A Contingency Perspective on the ConflictOutcome Relationship.” Research in Organizational Behavior 25 (January 2003): 187-242. doi:10.1016/s0191-3085(03)25005$\mathrm{x}$. .

[9] Leon-Perez, Jose M., Francisco J. Medina, Alicia Arenas, and Lourdes Munduate. "The Relationship between Interpersonal Conflict and Workplace Bullying." Journal of Managerial Psychology 30, no. 3 (April 13, 2015): 250-263. doi:10.1108/jmp-012013-0034.

[10] Rahim, M. Afzalur. “Managing Conflict in Organizations”, Quorum, Westort, CT (July 12, 2017). doi:10.4324/9780203786482.

[11] Oetzel, John G., and Stella Ting-Toomey. "Face Concerns in Interpersonal Conflict." Communication Research 30, no. 6 (December 2003): 599-624. doi:10.1177/0093650203257841.

[12] Thomas, Kenneth W. "Thomas-kilmann conflict mode." TKI Profile and Interpretive Report (2008): 1-11.

[13] Rahim, M. Afzalur. “A Measure of Styles of Handling Interpersonal Conflict.” Academy of Management Journal 26, no. 2 (June 1983): 368-376. doi:10.5465/255985.

[14] Putnam, Linda L., and Charmaine E. Wilson. "Communicative Strategies in Organizational Conflicts: Reliability and Validity of a Measurement Scale." Annals of the International Communication Association 6, no. 1 (January 1982): 629-652. doi:10.1080/23808985.1982.11678515.

[15] Saragih, Saut Pin Tub Ipar, and Harisno Harisno. "Influence of Knowledge Sharing and Information Technology Innovation on Employees Performance at Batamindo Industrial Park." CommIT (Communication and Information Technology) Journal 9, no. 2 (October 31, 2015): 45-49. doi:10.21512/commit.v9i2.1657. 
[16] Dell'Aquila, Elena, Federica Vallone, Maria Clelia Zurlo, and Davide Marocco. “Creating Digital Environments for Interethnic Conflict Management." Methodologies and Intelligent Systems for Technology Enhanced Learning, 9th International Conference, Workshops (June 25, 2019): 81-88. doi:10.1007/978-3-030-23884-1_11.

[17] Hocker, Joyce L., and W. W. Wilmot. "Interpersonal conflict 5th ed." Madison, WI: Brown \& Benchmark (1998).

[18] Apriyantopo, Wahyu, and Atik Aprianingsih. "Information Communication and Technology (ICT) Adoption in Asian Countries: An Empirical Evidence of Economic and Socio-Cultural Factors.” Binus Business Review 11, no. 3 (November 11, 2020 ): 175186. doi:10.21512/bbr.v11i3.6299.

[19] Marriner, A. "Managing conflict: comparing strategies and their use." Nursing Management 13, no. 6 (1982): 29-31.

[20] Zia, Sahibzada Yasar, Imran Saeed, and Naimat Ullah Khan. "Moderating Role of Emotional Intelligence in Conflict Resolution Strategies and Organizational Citizenship Behavior." The Journal of Humanities and Social Sciences 26, no. 1 (2018): 63-63.

[21] Anderson, Neil, Kristina Potočnik, and Jing Zhou. "Innovation and Creativity in Organizations." Journal of Management 40, no. 5 (March 17, 2014): 1297-1333. doi:10.1177/0149206314527128.

[22] Rosing, Kathrin, Ronald Bledow, Michael Frese, Nataliya Baytalskaya, Johanna Johnson Lascano, and James L. Farr. "The Temporal Pattern of Creativity and Implementation in Teams." Journal of Occupational and Organizational Psychology 91, no. 4 (June 19, 2018): 798-822. doi:10.1111/joop.12226.

[23] Shaw, Jason D., Jing Zhu, Michelle K. Duffy, Kristin L. Scott, Hsi-An Shih, and Ely Susanto. “A Contingency Model of Conflict and Team Effectiveness.” Journal of Applied Psychology 96, no. 2 (2011): 391-400. doi:10.1037/a0021340.

[24] Yong, Kevyn, Stephen J. Sauer, and Elizabeth A. Mannix. "Conflict and Creativity in Interdisciplinary Teams.” Small Group Research 45, no. 3 (May 19, 2014): 266-289. doi:10.1177/1046496414530789.

[25] Paletz, Susannah B. F., and Christian D. Schunn. “A Social-Cognitive Framework of Multidisciplinary Team Innovation.” Topics in Cognitive Science 2, no. 1 (January 2010): 73-95. doi:10.1111/j.1756-8765.2009.01029.x.

[26] Dyne, Linn, and Richard Saavedra. “A Naturalistic Minority Influence Experiment: Effects on Divergent Thinking, Conflict and Originality in Work-Groups.” British Journal of Social Psychology 35, no. 1 (March 1996): 151-167. doi:10.1111/j.20448309.1996.tb01089.x.

[27] De Dreu, Carsten K.W., and Annelies E.M. Van Vianen. "Managing Relationship Conflict and the Effectiveness of Organizational Teams.” Journal of Organizational Behavior 22, no. 3 (2001): 309-328. doi:10.1002/job.71.

[28] Van Woerkom, Marianne, and Marloes L. van Engen. "Learning from Conflicts? The Relations Between Task and Relationship Conflicts, Team Learning and Team Performance.” European Journal of Work and Organizational Psychology 18, no. 4 (December 2009): 381-404. doi:10.1080/13594320802569514.

[29] De Dreu, Carsten K. W. "When Too Little or Too Much Hurts: Evidence for a Curvilinear Relationship Between Task Conflict and Innovation in Teams.” Journal of Management 32, no. 1 (February 2006): 83-107. doi:10.1177/0149206305277795.

[30] De Dreu, Carsten K. W., and Laurie R. Weingart. "A Contingency Theory of Task Conflict and Performance in Groups and Organizational Teams." International Handbook of Organizational Teamwork and Cooperative Working (April 16, 2008): 151166. doi:10.1002/9780470696712.ch8.

[31] Anderson, Neil R., and Michael A. West. "Measuring climate for work group innovation: development and validation of the team climate inventory." Journal of Organizational Behavior: The International Journal of Industrial, Occupational and Organizational Psychology and Behavior 19, no. 3 (1998): 235-258. doi:10.1002/(SICI)1099-1379(199805)19:3<235::AIDJOB837>3.0.CO;2-C.

[32] Jehn, Karen A., and Elizabeth A. Mannix. "The Dynamic Nature of Conflict: A Longitudinal Study of Intragroup Conflict and Group Performance.” Academy of Management Journal 44, no. 2 (April 2001): 238-251. doi:10.5465/3069453.

[33] Yu, Lingtao, and Mary Zellmer-Bruhn. "Introducing Team Mindfulness and Considering Its Safeguard Role Against Conflict Transformation and Social Undermining." Academy of Management Journal 61, no. 1 (February 2018): $324-347$. doi:10.5465/amj.2016.0094.

[34] Tafvelin, Susanne, Britt-Inger Keisu, and Elin Kvist. "The Prevalence and Consequences of Intragroup Conflicts for Employee Well-Being in Women-Dominated Work.” Human Service Organizations: Management, Leadership \& Governance 44, no. 1 (September 18, 2019): 47-62. doi:10.1080/23303131.2019.1661321.

[35] Brislin, R. W. The wording and translation of research instruments. In W. J. Lonner \& J. W. Berry (Eds.), Field methods in cross-cultural research. Sage Publications, Inc. (1986): 137-164.

[36] Reinartz, Werner, Michael Haenlein, and Jörg Henseler. "An Empirical Comparison of the Efficacy of Covariance-Based and Variance-Based SEM." International Journal of Research in Marketing 26, no. 4 (December 2009): $332-344$. doi:10.1016/j.ijresmar.2009.08.001. 
[37] Chin, Wynne W., and Peter R. Newsted. "Structural equation modeling analysis with small samples using partial least squares." Statistical strategies for small sample research 1, no. 1 (1999): 307-341.

[38] Hair Jr, Joseph F., Marko Sarstedt, Christian M. Ringle, and Siegfried P. Gudergan. "Advanced issues in partial least squares structural equation modeling." SAGE Publications, (2017).

[39] Fornell, Claes, and David F. Larcker. "Evaluating Structural Equation Models with Unobservable Variables and Measurement Error." Journal of Marketing Research 18, no. 1 (February 1981): 39-50. doi:10.1177/002224378101800104.

[40] Henseler, Jörg, Christian M. Ringle, and Marko Sarstedt. "A New Criterion for Assessing Discriminant Validity in VarianceBased Structural Equation Modeling.” Journal of the Academy of Marketing Science 43, no. 1 (August 22, 2014): 115-135. doi:10.1007/s11747-014-0403-8.

[41] Darawong, Chonlatis. "Conflict Management Styles and Interpersonal Conflict between Marketing and R\&D Personnel during the New Product Development Process.” International Journal of Innovation and Technology Management 14, no. 06 (November 9, 2017): 1750034. doi:10.1142/s0219877017500341.

[42] Özkalp, Enver, Zerrin Sungur, and Aytül Ayşe Özdemir. "Conflict Management Styles of Turkish Managers.” Journal of European Industrial Training 33, no. 5 (June 5, 2009): 419-438. doi:10.1108/03090590910966571.

[43] Sunindijo, Riza Yosia, and Bonaventura H. W. Hadikusumo. "Emotional Intelligence for Managing Conflicts in the Sociocultural Norms of the Thai Construction Industry." Journal of Management in Engineering 30, no. 6 (November 2014): 04014025. doi:10.1061/(asce)me.1943-5479.0000211.

[44] Saeed, Tahir, Shazia Almas, M. Anis-ul-Haq, and GSK Niazi. "Leadership Styles: Relationship with Conflict Management Styles.” International Journal of Conflict Management 25, no. 3 (July 8, 2014): 214-225. doi:10.1108/ijcma-12-2012-0091.

[45] Su'udy, Rizaladdin. "Conflict management styles of Americans and Indonesians: exploring the effects of gender and collectivism/individualism." PhD diss., University of Kansas, (2009).

[46] Menguc, Bulent, and Seigyoung Auh. "Conflict, Leadership, and Market Orientation.” International Journal of Research in Marketing 25, no. 1 (March 2008): 34-45. doi:10.1016/j.ijresmar.2007.08.001.

[47] Cohen, Jacob. "Statistical Power Analysis for the Behavioral Sciences." Academic Press, (2013). 


\section{Appendix I}

\section{Conflict Management Styles}

IS1: I try to investigate an issue with my other team members to find a solution acceptable to us.

IS2: I try to integrate my ideas with those of my other team members to come up with a decision jointly.

IS3: I try to work with my other team members to find solutions to a problem which satisfy our expectations.

IS4: I exchange accurate information with my other team members to solve a problem together.

IS5: I try to bring all our concerns out in the open so that the issues can be resolved in the best possible way.

IS6: I collaborate with my other team members to come up with decisions acceptable to us.

IS7: I try to work with my other team members for a proper understanding of a problem.

\section{Obliging Style (OS)}

OS1: I generally try to satisfy the needs of my other team members.

OS2: I usually accommodate the wishes of my other team members.

OS3: I give in to the wishes of my other team members.

OS4: I often go along with the suggestions of my other team members.

OS5: I try to satisfy the expectations of my other team members.

\section{Dominating Style (DS)}

DS1: I use my influence to get my ideas accepted.

DS2: I use my authority to make a decision in my favour.

DS3: I sometimes use my power to win a competitive situation.

\section{Task Conflict}

How much conflict of ideas is there in your team?

How frequently do you have disagreements within your team about the task of the project you are working on?

How often do people in your team have conflicting opinion about the project you are working on?

\section{Team Innovation}

My team is always moving toward the development of new answers.

Assistance in developing new ideas is readily available.

My team is open and responsive to change.

In the team we take the time needed to develop new ideas.

People in the team co-operate to help develop and apply new ideas.

Members of the team provide and share resources to help in the application of new ideas. 